\title{
Bacteriological Profile in Urinary Tract Infection and Their Antibiotic Susceptibility Pattern
}

\author{
Indira Basnet ${ }^{1}$, Mahesh Kumar Chaudhary ${ }^{2}$, Santosh Khanal ${ }^{1}$, Om Prakash Panta ${ }^{1}$, Pramod Poudel ${ }^{1 *}$ \\ ${ }^{1}$ Department of Microbiology, National College, Khusibu, Kathmandu, Nepal \\ ${ }^{2}$ KIST Medical College and Teaching Hospital, Imadol, Lalitpur, Kathmandu, Nepal
}

\begin{abstract}
Urinary tract infection (UTI) is common and serious health problem affecting millions of people worldwide each year especially females. Treatment of UTI relies on the bacteriological profile and the knowledge of their antibiotic susceptibility pattern. A cross-sectional study was done in Kantipur Hospital, Kathmandu. Tools for data collection were a data collection form. Total 1246 urine sample from patient suspected of UTI was reviewed, out of which 369 (29.61\%) of urine sample showed significant growth. UTI was prevalent in females of age group 21-30 being Escherichia coli (62.3\%) predominant one. Altogether 199 multi drug resistance strains were isolated. Empirical treatment of UTI should be discouraged.
\end{abstract}

Key words: Urinary tract infection, mid-stream urine, multi drug resistance

\section{INTRODUCTION}

UTI is defined as persistence present and proliferation of active microorganism in the urethra. UTI is common infection affecting people of all age and gender. However, women in reproductive age are at high risk ${ }^{1}$. One woman in five develops a UTI during their lifetime. UTI is a heterogeneous disease which is categorized as either community acquired or hospital acquired UTI, asymptomatic or symptomatic UTI and complicated or uncomplicated $\mathrm{UTI}^{2}$. Uncomplicated UTI are only associated with bacterial infection mainly caused by Escherichia coli whereas complicated UTI occur in both men and women as a result of catheter used in hospital setting, bladder and kidney dysfunction or kidney

\section{*Corresponding author:}

poudel.pm@gmail.com transplant. Major causative agents for UTI are E. coli, KLebsiella species, Proteus species, Pseudomonas species, Staphylococcus species and Streptococcus species ${ }^{3}$. In medical aspect, antibiotics have been used either for prophylaxis, empiric therapy or pathogen directed therapy which contributes the central role in control and management of infectious diseases. Antibiotics resistance that is developed in pathogenic microorganism is becoming a global problem and plasmids have been found responsible for encoding antimicrobial resistance in pathogenic bacteria $^{4}$.

\section{Materials and Methods}

A cross-sectional study was conducted in Kantipur Hospital, Tinkune, Kathmmandu, Nepal in 2015. Inclusion criteria for the study were the data of patient suspected of UTI and antibiotic susceptibility pattern that were from six 
Joshi et al. International Journal of Medicine and Biomedical Sciences 2017; 2(4): 1-6

months back during time of study and exclusion criteria were data other antibiotic susceptibility pattern other than UTI. Here, total 1246 urine sample from patients suspected

\section{Results}

Out 369 UTI patients, higher percentage of female patient (54\%),were found within age group 21-30 years.

However, percentage was low in children below 10 years.

Table 1 Age and Gender Distribution among UTI patients

\begin{tabular}{llll}
\hline \multirow{2}{*}{ Age group } & No. of UTI patient & & Gender \\
\cline { 3 - 4 } & & Male $(\%)$ & Female $(\%)$ \\
\hline$<10$ & 1 & 0 & $1(0.5)$ \\
$20-$ Nov & 47 & $15(12.2)$ & $32(13)$ \\
$21-30$ & 196 & $63(51.2)$ & $133(54)$ \\
$31-40$ & 56 & $30(24.4)$ & $26(10.6)$ \\
$41-50$ & 42 & $6(4.9)$ & $36(14.6)$ \\
$51-60$ & 13 & $3(2.4)$ & $10(4.1)$ \\
$61-70$ & 10 & $4(3.3)$ & $6(2.4)$ \\
$>70$ & 4 & $2(1.6)$ & $2(0.8)$ \\
\hline Total & & 369 & $246(66.67)$ \\
\hline
\end{tabular}

\section{Percentage of Different Isolated Organisms}

Highest percentage was observed in E.coli (62.3) and lowest (0.5) in Citrobacter sp. Enterobacter sp.

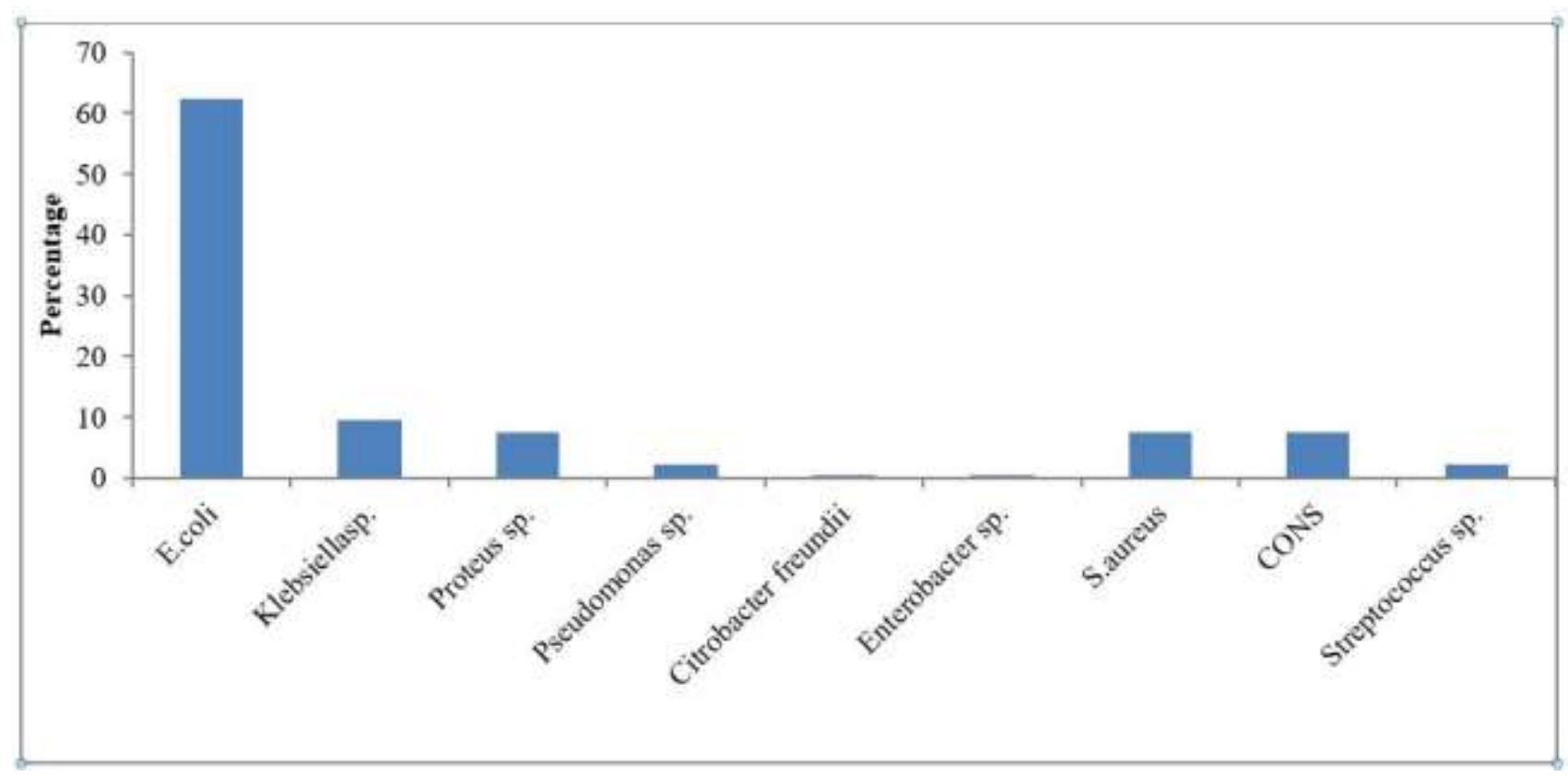

Figure 1: Percentage of Different Isolated Organisms 
Antibiotic susceptibility Pattern and MDR Strains of Bacterial Isolates

Table 2: Antibiotic susceptibility Pattern and MDR Strains of Bacterial Isolates

\begin{tabular}{|c|c|c|c|c|c|c|c|c|c|c|}
\hline Antibiotics $(\%) \rightarrow$ & \multirow[t]{2}{*}{ AMP } & \multirow{2}{*}{ NA } & \multirow{2}{*}{ NX } & \multirow{2}{*}{ NIT } & \multirow{2}{*}{ OF } & \multirow{2}{*}{ GEN } & \multirow{2}{*}{ COT } & \multirow[t]{2}{*}{$\mathrm{E}$} & \multirow{2}{*}{ CIP } & \multirow{2}{*}{$\operatorname{MDR}(\%)$} \\
\hline Organism $\downarrow$ & & & & & & & & & & \\
\hline E.coli & 40.43 & 29 & 76 & 90 & 71 & 80.4 & 50.8 & - & 59.5 & $128(64.3)$ \\
\hline Klebsiella sp. & 22.8 & 37 & 74 & 86 & 71 & 97.1 & 51.4 & - & 37.1 & $16(8.1)$ \\
\hline Proteussp. & 21.4 & 21 & 82 & 71 & 64 & 78.5 & 32.1 & - & 57.1 & $14(7.0)$ \\
\hline Pseudomonas sp. & 12.5 & 25 & 88 & 88 & 75 & 100 & 37.5 & - & 62.5 & $3(1.5)$ \\
\hline C.freundii & 0 & 50 & 100 & 50 & 50 & 100 & 0 & - & 50 & - \\
\hline Enterobacter sp. & 0 & 100 & 100 & 100 & 50 & - & 0 & - & 100 & - \\
\hline S.aureus & 46.4 & - & 25 & - & 25 & 89.3 & 42.8 & 25 & 14.2 & 23(11.6) \\
\hline CoNS & 69.4 & - & 67 & - & 67 & - & 44.4 & 56 & 55.6 & $13(6.5)$ \\
\hline Streptococcussp. & 69.4 & - & 67 & - & 67 & - & 44.4 & 56 & 55.6 & $2(1)$ \\
\hline Total & & & & & & & & & & 199(100) \\
\hline
\end{tabular}

\section{Discussion}

The age and gender group analysis shows that female patients in the range of 21-30 years are highly affected by UTI and least in the children below 10, this might be due to reason that age group 21-30 are in reproductive age group which has high rate of UTI. The bacterial isolates found in this study are similar to bacterial isolates identified in other studies conducted in different parts of the World under different conditions, host factors, health practices and socio-economic status ${ }^{5}$.

Among different bacterial isolates the most predominant organism was found to be E.coli (62.3\%) followed by Klebsiella sp. (9.5\%),.Proteussp. (7.6\%), Pseudomonas sp.(2.2\%), C.freundii (0.5\%), Enterobacter sp. (0.5\%), S.aureus (7.6\%), CoNS (7.6\%) and Streptococcus sp. (2.2\%). Several other researchers have also reported the predominance of E.coli and other bacterial isolates respectively (Dhakal et al 2001, Farrellet al 2003). Out the total 369 bacterial isolates, 199 MDR strains where bacterial isolates evaluated for 9 different antibiotics. Here, MDR criterion was resistance to three or more antibiotics (Kurupete 2005). The resistance to andtibiotics may be due to broad spectrum antibiotics prescribed empirically or due to transmission of resistance isolates through plasmid ${ }^{6}$

\section{Conclusion}

Out of 1246 urine sample, a total of 369 (29.61\%) bacteria belonging to 8 different genera were isolated. Gram negative bacteria were found predominant and E. coli was the major etiological agent of UTI with $62.3 \%$ while in case of Gram positive, S. aureus were frequently isolated in urine cultures. Nitrofurantoin was effective against almost all bacteria. Moreover, 199 (53.93\%) bacterial isolates were found to be MDR with highest $82.14 \%$ in S. aureus and $50 \%$ in Proteus sp.

\section{References}

1. Anjum MU, Khan MS, Shahid AR, Shah SH (2016). Urinary tract infection: etiological profile and antimicrobial susceptibility patterns of 
Uropathogens. Professional Med J 23(1): 010014 .

2. Dash M, Padhi S, Mohanty I, Panda P and Parida B (2013). Antimicrobial resistance in pathogens causing urinary tract infections in a rural community of Odisha, India. Jounal of family and Community Medicine 20(1): 20-26.

3. Foxman B (2010). Epidemiology of urinary tract infections: Nature Reviews Urology. 7: 653-660.

4. Kurupete S, Surucuoglu S, Sezgin C, Gazi H, Gulay M and Ozbakkaloglu (2005). Increasing Antimicrobial Resistance in E. coli Isolates from Community-Acquired Urinary Tract Infections during 1998-2003 in Manisa, Turkey. J Infect Dis 58:159-161.
5. Dhakal BK and Pokharel BM (2001). Microbiology of urinary tract infection. J Nep Assoc Med Lab Sci 3:9-12.

6. Kattel HP, Acharya J, Mishra SK, Rijal B and Pokhrel BM (2008). Bacteriology of urinary tract infection among patients attending Tribhuvan University Teaching Hospital, Kathmandu. J Nepal for Med Assoc 9(1): 25-29.

7. Farrell DJ, Morrisey I, Rubies D, Robbins M and Felmingham D (2003). A UK multicentre study of the antimicrobial susceptibility of bacterial pathogens causing UTI. J Infect 46: 94-100. 